\section{ambient \\ SCIENCE \\ Vol. 05(Sp1):20-23 \\ Year 2018}

\title{
The Relationship between Sexual Function and Quality of Life in Reproductive-age grouped Women in Iran: A Cross-Sectional Study
}

\section{Safieh Jamali', Reza Inaloo ${ }^{2}$, Shohreh Javadpour ${ }^{3}$, Marzieh Haghbeen ${ }^{3}$, Neda Poornowrooz ${ }^{3 *}$}

'Research Center for Social Determinants of Health, Jahrom University of Medical Sciences, Jahrom, Iran

${ }^{2}$ Department of Urology, Jahrom University of medical sciences, Jahrom, Iran

${ }^{3}$ Department of Nursing and Midwifery, Jahrom University of Medical Sciences, Jahrom, Iran

Study Area: Jahrom, Iran

Coordinates: $28^{\circ} 30^{\prime}{ }^{\prime \prime \prime} \mathrm{N} ; 53^{\circ} 33^{\prime} 38^{\prime \prime} \mathrm{E}$

Key words: QoL, Sexual desire, Arousal, Sexual satisfaction, Lubrication, Pain, Children

The research was approved by the ethics council of Jahrom University of Medical Sciences (IR.JUMS.REC.1395.109).

\section{Introduction:}

Quality of life (QoL) is one of the key issues in the field of sexual health and fertility (Lazdane et al., 2011), which directly relates with various important factors, goals, expectations, standards, and priorities of one's life (Krageloh et al., 2011). QoL is completely subjective to one's understanding of self-oriented sexual desires (Lottes \& Kontula, 2000). QoL can be a defined as the health and overall life quality of people living in the society (WHO, 2002). A factor associated with a better QoL is his/her sexual satisfaction (Yucel \& Gassanov. 2010). One of the major indicator used in most of the existing studies to investigate this concept is the incidence of sexual dysfunction, which is directly related to the lack of desire, arousal, orgasm, and dyspareunia (APA, 2013). A multitude of anatomical, physiological, medical, and psychological complications give rise to sexual dysfunction that can have negative impacts on QoL, interpersonal relationships, women's self-esteem, including physical and mental health (Berman et al., 2003; Salonia et al., 2004). The prevalence of these disorders among 18-59 years old American women (Laumann et al., 1999), Turkish women (Cayan et al., 2004), and Iranian women (Safarinejad, 2006) was reported as $43 \%, 46.9 \%$, and $31.5 \%$, respectively. Some reports suggested, sexual dysfunction is affected by one's age, an age of one's marriage, menopause, lifestyle,

\section{Abstract}

Quality of life (QoL) is one of the important health consequences that play an important role in the implementation and evaluation of health interventions. Sexual function is also one of the crucial factors, affecting QoL in women. We tried to understand the relationship between sexual function and QoL in reproductive-age grouped women of Iran through a cross-sectional study performed on 459 subjects who were referred to the Jahrom Women Clinic. Data were based on the sexual function related including some preliminary QoL related questionnaire which were further statistically analyzed. Significant relationships were evident for the sexual function dependent on age, education, occupation, husband's education, parity, and on the number of children. Study witnessed that the sexual function was one of the important factors that can affect QOL in reproductive-age grouped women.

emotional problems (Rosen, 2000), the use of drugs and diseases (Clayton \& Valladares Juarez, 2010), and hypertension (Kütmeç \& Yurtsever, 2011).

Inappropriate sexual relations and sexual dissatisfaction develops marital conflicts and disintegration in families, whereas those who are highly satisfied with their husbands' sexual relations lead a better QoL. Indeed, dissatisfaction with sexual relationships can lead to serious problems in couples' relations resulting hatred of the spouse (Mulaviverdenjani et al., 2014). Fan \& Lui (2004) reported a statistically dependant relationship between marital satisfaction and the quality of marital life. Based on a study on the United States Symond et al. (2005) reported that sexual satisfaction was one of the most important factors in the quality of marital life in women. Considering that QoL is a context-based concept in each society, and given the role of this variable in public communications, improvement of interpersonal relationships, promotion of general QoL especially in women, and finally preserving, consolidating, and boosting family and society health, this study was an attempt to investigate the association between QoL and sexual function.

\section{Methodology:}

This cross-sectional study was carried out on 459 women 
aged in betweenı-49 years who were referred to health clinics and medical centers affiliated to Jahrom University of Medical Sciences during the year 2018. The women were sampled through convenience method and were enrolled in the study on tyhe basis of inclusion criteria; namely literate women, Iranian nationality, no history of underlying chronic diseases (blood pressure, blood glucose), no history of smoking, alcohol, and antidepressants, and no history of stressful events (deaths of relatives and divorce) then in the past six months. Exclusion criteria were removal of incomplete questionnaires and discontentedness of participating in the research. Data gathering tool was a three-part questionnaire; first part containing personal information (age, education, occupation, spouse's education and job, parity, number of children, etc.), second part consisted of QoL questionnaire, and the third part included an index for women's sexual function assessment.

The WHOQoL-BREF scale was used to measure QoL, which consisted of 26 questions related to the assessment of QoL and its variables, including four domains of QoL; physical health, mental health, environmental health, social relationships. In addition to it, two general questions to evaluate the QoL and health were also included. Based on the scoring information provided in the questionnaire's guide, each domain was scored between 0-10o, i.e., a higher score indicating a better status and a lower score showing further problems in that domain (Bonomi et al., 2000). Nejat et al. (2006) validated the questionnaire in Iran with a Cronbach's alpha correlation coefficient of $>70 \%$ in all domains and also a confirmed appropriate reliability. Female sexual function index was used to measure sexual performance which was with 19 questions for assessing people in six domains of libido ( 2 ques.), sexual stimulation (4 ques.), lubrication (4 ques), orgasm (3 quest.), sexual satisfaction (3 ques.), and pain (3 ques.). The questions were scored based on a scoring system from zero to 5 , and the score of each domain was obtained through the sum of questions in that domain multiplied by its factor coefficient. Finally, the total score of sexual function was obtained from sum of all the domains with a scale from 2 to 36 (Rosen et al., 2000; Meston, 2003). The relationship between demographic variables and sexual function were examined by employed ANOVA. Also, the QoL domains between the two groups of women with/without sexual dysfunction were compared byt-test.

\section{Results:}

The mean age of women was $31.8 \pm 7.64$ years where a majority (8o.6\%) was of the housewives. From the total, the majority $(36 \%)$ was having an education level of diploma (Table-1). The results of t-test and ANOVA revealed significant relationships between sexual function and demographic factors, mainly with respect to the age ( $\mathrm{p}<\mathrm{o.001})$, education $(\mathrm{p}<\mathrm{o} .0001)$, occupation ( $\mathrm{p}$ $<0.009)$, spouse's education $(\mathrm{p}<0.0001)$, parity $(\mathrm{p}<0.001)$, and number of children $(\mathrm{p}<0.001)$ (Table-1).

Table-2 shows comparisons of QoL between two groups of women with/without sexual dysfunction. Women with impaired sexual function presented lower mean scores in all QoL domains, which was statistically significant in the physical $(\mathrm{p}<0.003)$, psychological ( $<0.001$ ), environmental ( $p<0.001)$, and social $(\mathrm{p}<\mathrm{o.001})$ domains.

Table-1: Demographic characteristics of the participants and its association with sexual function $(n=459)$

\begin{tabular}{|c|c|c|c|}
\hline \multirow{2}{*}{ Characteristics } & \multirow[t]{2}{*}{$\mathrm{N}(\%)$} & FSFI Score Mean \pm SE & \multirow[t]{2}{*}{ p-value } \\
\hline & & & \\
\hline$<25$ & $114(24.8)$ & $24.16 \pm 0.65$ & $<0.001$ \\
\hline $26-35$ & $201(43.8)$ & $23.42 \pm 0.42$ & \\
\hline$>35$ & $144(31.4)$ & $21.39 \pm 0.56$ & \\
\hline \multicolumn{4}{|l|}{ Educational level } \\
\hline Elementary & $53(11.5)$ & $20.66 \pm 1.04$ & $<0.0001$ \\
\hline Intermediate & $72(15 \cdot 7)$ & $21.90 \pm 0.68$ & \\
\hline High school & $42(9.2)$ & $20.08 \pm 1.10$ & \\
\hline Diploma & $127(27.7)$ & $23.48 \pm 0.53$ & \\
\hline Academic & $165(35.9)$ & $24 \cdot 5^{1 \pm 0.49}$ & \\
\hline \multicolumn{4}{|l|}{ Employment status } \\
\hline Housewife & $370(80.6)$ & $22.95 \pm 0.32$ & $>0.9$ \\
\hline Employed & $89(19 \cdot 4)$ & $23.03 \pm 0.83$ & \\
\hline \multicolumn{4}{|c|}{ Husband's Education } \\
\hline Elementary & $57(12.4)$ & $0.88 \pm 0.98$ & $<0.0001$ \\
\hline Intermediate & $114(24.8)$ & $22.26 \pm 0.59$ & \\
\hline High school & $32(7)$ & $20.71 \pm 1.15$ & \\
\hline Diploma & $129(28.1)$ & $23.24 \pm 0.48$ & \\
\hline Academic & $127(27.7)$ & $24.82 \pm 0.61$ & \\
\hline \multicolumn{4}{|c|}{ Husband's Occupation } \\
\hline Non-employed & $352(76.7)$ & $22.42 \pm 0.35$ & $<0.001$ \\
\hline Employed & $107(23 \cdot 3)$ & $24.77 \pm 0.64$ & \\
\hline \multicolumn{4}{|l|}{ Number of delivery } \\
\hline$<3$ & $352(76.7)$ & $23.51 \pm 0.35$ & $<0.001$ \\
\hline$>3$ & $107(23 \cdot 3)$ & $21.18 \pm 0.64$ & \\
\hline \multicolumn{4}{|l|}{ Number of children } \\
\hline$<3$ & $367(80)$ & $23.51 \pm 0.33$ & $<0.001$ \\
\hline$>3$ & $92(20)$ & $21.18 \pm 0.72$ & \\
\hline
\end{tabular}

Table-2: Comparison of QoL between two groups of pregnant women with sexual dysfunction and without sexual dysfunction

\begin{tabular}{llll}
\hline Quality of life domains & $\begin{array}{l}\text { FSFI }<26.5 \\
(n-316)\end{array}$ & $\begin{array}{l}\text { FSFI }<26.5 \\
(n-143)\end{array}$ & pvalue \\
\hline Physical & $21.07 \pm 0.21$ & $22.18 \pm 0.30$ & $<0.003$ \\
Psychological & $19.46 \pm 0.20$ & $21.49 \pm 0.25$ & $<0.001$ \\
Economic & $22.11 \pm 0.24$ & $24.32 \pm 0.31$ & $<0.001$ \\
Social & $9.67 \pm 0.22$ & $10.95 \pm 0.18$ & $<0.001$ \\
Total score of the QoL & $72.14 \pm 0.64$ & $78.95 \pm 0.81<0.001$ \\
\hline
\end{tabular}

The results in Table- 3 indicate significant positive correlations between all aspects of sexual function and QoL domains, with the highest correlation recorded between the total score of sexual function and the environmental domain of QoL $(\mathrm{r}=0.28, \mathrm{p}<0.0001)$. 
Ambient Science, 2018: Vol. 05(Sp1); 20-23

DOI:10.21276/ambi.2018.05.sp1.ta02

Table-3: Correlation coeff icient between QoL with sexual function in women

\begin{tabular}{llllll}
\hline $\begin{array}{l}\text { QoL/Sexual } \\
\text { function }\end{array}$ & $\begin{array}{l}\text { Physi- } \\
\text { cal }\end{array}$ & $\begin{array}{l}\text { Psycholo } \\
\text { gical }\end{array}$ & $\begin{array}{l}\text { Econo- } \\
\text { mic }\end{array}$ & Social & Total score \\
\hline Desire & $0.1^{*}$ & $0.5^{* *}$ & $0.17^{* *}$ & $0.2^{* *}$ & $0.23^{* *}$ \\
Arousal & $0.2^{* *}$ & $0.4^{* *}$ & $0.35^{* *}$ & $0.26^{* *}$ & $0.39^{* *}$ \\
Lubrication & 0.07 & $0.7^{* *}$ & $0.2^{* *}$ & $0.18^{* *}$ & $0.23^{* *}$ \\
Orgasm .- & $0.09^{*}$ & $0.2^{* *}$ & $0.23^{* *}$ & $0.21^{* *}$ & $0.26^{* *}$ \\
Satfaction & & & & & \\
Pain & 0.06 & -0.6 & 0.05 & 0.06 & 0.04 \\
Total Score & $0.13^{* *}$ & $0.13^{* *}$ & $0.28^{* *}$ & $0.25^{* *}$ & $0.32^{* *}$ \\
\hline
\end{tabular}

P value *. Correlation is signif icant at the 0.05 level

$\mathrm{P}_{\text {value }}{ }^{* *}$. Correlation is significant at the o.or level

\section{Discussion:}

This is the first study in Iran to investigate the relationship between sexual function and demographic parameters with respect to the effects of sexual function on Quality of Life (QoL) in women belonging to reproductive age group. The findings revealed a sexual dysfunction among $68.8 \%$ of the studied women, which was significantly related to the increasing ages of the women revealed sexual dysfunction. Earlier, Jaafarpour et al. (2013) reported a sexual dysfunction among $42 \%$ in Iran, which increased in women over 40 years of age. Cayan et al. presented evidence of a sexual dysfunction among $46.9 \%$ women aged between 18-66 years old women revealed a rising trend with age (Cayan et al., 2004). Abedi et al. (2014) also reported the association of age with sexual dysfunction, all of which strengthen our study. Our findings strongly support that the women including their husbands having strong academic background enjoy higher sexual satisfaction. Moreover, employed women and husbands achieved higher scores of sexual function, which is in agreement with Abed et al. (2014); Çilli, et al. (2006) Jaafarpour et al. (2013), Telsiz (1998), and Safarinejad (2006). It seems that high-educated employed women are more able to cope with the bitter experience and solve the marital problems. Most studies also identified that the education level plays a major role in improving social relations and marital-related problems. Women with greater parity and children reported a lower sexual function. Pregnancy followed by vaginal delivery, especially parity, targets pelvic organ prolapse and, consequently, affect sexual function (Gibbs et al., 2008). Sexual dissatisfaction depends on the degree of vaginal and perineal looseness, which is considered as an indication for sexual dysfunction (Shull, 1999; Berek, 2007), as was also pointed out by Jamali et al. (2014) \& Abedi et al. (2015). Thus, women with more children (vaginal births) exhibited relatively low sexual satisfaction.

Our findings indicated that women with sexual dysfunction scored lower in terms of physical, mental, social, and environmental subjects of QoL. On the other hand, sexual function was positively correlated with all aspects of QoL, that is, satisfaction with sexual function rises by increasing the dimensions of QoL.

Sexual dysfunction is a multidimensional and multifactorial problem that greatly impacts QoL and interpersonal relationships (Ambler et al., 2012). A global study on the attitude and sexual behavior of women aged in between $40-80$ years from 29 countries demonstrated that sexual dysfunction had a significant impact on women's QoL (Laumann et al., 2005). Another study conducted on 2196 postmenopausal women reported that the sexual satisfaction also could be an important aspect of QoL or well-being in such women (Park et al., 2003). Sexual dysfunction, therefore, can reduce the QoL in women and their overall satisfaction with marital life (Ramezani et al., 2014). Couples even facing sexual complication could lead to a higher loss of QoL (Tepavcevic et al., 2008). As per our results, a total score of QoL had the highest positive correlation with the arousal. Pre-sexual readiness is the first-factor affecting sexual QoL in women. Women evaluate the readiness level with the level of psychosocialphysical motivation and fondling. Many researchers agreed that acquiring necessary preparation before sexual intercourse by women is one of the most important factors affecting sexual function and the resultant feeling of satisfaction. These factors play a more stimulating role in the sexual response of a woman in comparison with bodily factors and physical stimuli (Basson, 2002).

Finally, it could be concluded that the women with sexual dysfunction have lower QoL levels than those without sexual dysfunction. In addition, variables such as age, occupation, education, parity, and a number of children are factors affecting sexual function. However, this study was conducted on women referred to public health clinics in Jahrom, hence, the results may not reflect the whole population. Because of the cultural and religious limitations in our society, people might not be able to easily express their sexual issues, so the likely lack of trueness in some people to explicitly express their issues was beyond the control of the researcher.

\section{Acknowledgment:}

This study is the result of a research project approved by Jahrom University of Medical Sciences. The authors appreciate the support by the research deputy and all the participants who assisted in the implementation of this project.

\section{References:}

Abedi, P., Jamali, S., Tadayon, M., Parhizkar, S. \& Mogharab, F., (2014): Effectiveness of selective vaginal tightening on sexual function among reproductive aged women in Iran with vaginal laxity: A quasi-experimental study. L Obstet. Gynaecol. Res., 40(2):526-531.

Ambler, D.R., Bieber, E.J. \& Diamond, M.P. (2012): Sexual function in elderly women: a review of current literature. Rev. Obstet. Gynecol.,5(1):16-27. 
APA (American Psychiatric Association. ) (2013): Sexual and gender identity disorders, in: Diagnostic and Statistical Manual of Mental Disorders (5th ed., text rev.). Pub. by: Amer Psychiatric Pub Incorporated, Washington, DC: Author. p. 991.

Basson, R. (2002): A model of women's sexual arousal. J Sex Marital Ther., 28(1):1-10.

Berek, S.J. (2007): Berek and Novak's Gynecology. 14th. Pub. by: Lippincott Williams \& Wilkins, Philadelphia. 1671 p.

Berman, J.R., Berman, L.A. \& Kanaly, K.A. (2003): Female Sexual Dysfunction: New Perspectives on Anatomy, Physiology, Evaluation and Treatment. EAUUpdateSer., 1(3):166-177.

Bonomi, A.E., Patrick, D.L., Bushnell, D.M. \& Martin, M. (200o): Validation of the United States' version of the World Health Organization Quality of Life (WHOQoL) instrument. I Clin Epidemiol., 53(1):19-23.

Cayan, S., Akbay, E., Bozlu, M., Canpolat, B., Acar, D. \& Ulusoy, E. (2004). The prevalence of female sexual dysfunction and potential risk factors that may impair sexual function in Turkish women. Urol. Int., 72(1):52-57.

Çilli, A.S., Kaya, N., Bodur, S. \& Özkan, I., Kucur, R. (2006): A comparative analysis os the psychological symptoms observed in the working women and housewives.(Source: https://www.scribd.com).

Clayton, A.H. \& Valladares Juarez, E.M. (2010): Female sexual dysfunction. Psychiatr. Clin. NorthAm.,40(2):267-284.

Fan, C.S., \& Lui, H.K. (2004). Extramarital Affairs, Marital Satisfaction, and Divorce: Evidence from Hong Kong, Contemp. Eco. Policy, 22(4):442-445.

Gibbs, R.S., Karlan, B.Y., Haney, A.F., Nygard, I. (2008): Danforth's Obstetrics and Gynecology 1oth Edition (English). Pub. by : Lippincott Williams \& Wilkins. 1136p.

Jaafarpour, M., Khani, A., Khajavikhan, J. \& Suhrabi, Z. (2013): Female Sexual Dysfunction: Prevalence and Risk Factors. $]$. Clin. Diagn. Res., 7(12):2877-2880.

Jamali S, Abedi, P., Rasekh, A. \& Mohammadjafari, R. (2014): The Long Term Effect of Elective Colpoperineoplasty on Sexual Function in the Reproductive Aged Women in Iran.Int. Sch. Res. Notices.,2014:Article ID 912786, 1-5.

Krageloh, C.U., Henning, M.A., Hawken, S.J., Zhao, Y., Shepherd, D. \& Billington, R. (2011): Validation of the WHOQoL-BREF quality of life questionnaire for use with medical students. Educ. Health (Abingdon). 24(2):545.

Kütmeç, C. \& Yurtsever, S. (2011): Effects of sexual function of essential hypertensions in women. Eur. J. Cardiovasc. Nurs., 10(1):56-63.

Laumann, E.O., Paik, A. \& Rosen, R.C. (1999): Sexual dysfunction in the United States: prevalence and predictors. LAMA, 281(6):537-544.

Laumann, E.O., Nicolosi, A., Glasser, D.B., Paik, A., Gingell, C., Moreira, E. \& Wang, T. (2005): Sexual problems among women and men aged 40-80 y: prevalence and correlates identified in the Global Study of Sexual Attitudes and Behaviors. Int. J. Impot. Res., 17(1):39-57.

Lazdane, G., Avery, L. \& Persson, J. (2011): Sexual health: a public health challenge in Europe. Entre Nous, 72:1-32.

Lottes, I. \& Kontula, O. (2000): New views on sexual health. The case of Finland. Pub. by: Population Research Institute,
Series D 37/2000 9339.

Meston, C.M. (2003): Validation of the Female Sexual Function Index (FSFI) in women with female orgasmic disorder and in women with hypoactive sexual desire disorder.J Sex Marital Ther. 29(1):39-46.

Mulaviverdenjani, A., Hekmat, K.H., Afshari, P., \& Hosini, S.M. (2014). Functional and sexual satisfaction after mastectomy, Iranian Women. Obstet. Infert. J., 17(124):17-24. (Persian).

Nejat, S., Montazeri, A., Naieni, A.H., Mohammad, K. \& Majdzadeh, S.R. (2006): The World Health Organization quality of Life (WHOQoL-BREF) questionnaire: Translation and validation study of the Iranian version. J. Sch. Pub. Health Tehran Inst. Pub. Health Res., 4(4):1-12.

Park, Y.J., Kim, H.S., Chang, S.O., Kang, H.C.,Chun, S.H. (2003): Sexuality and related factors of postmenopausal Korean women. Taehan Kanho Hakhoe Chi., 33(4):457-463.

Abedi, P., Afrazeh, M., Javadifar, N. \& Saki, A. (2015): The Relation Between Stress and Sexual Function and Satisfaction in Reproductive-Age Women in Iran: A Cross-Sectional Study. I SexMarital Ther., 41(4):384-90.

Ramezani, T.F., Farahmand, M., Simbar, M. \& Afzali, M.H. (2014): Factors associated with sexual dysfunction; a population based study in Iranian reproductive age women. Arch. Iran. Med., $17(10): 679-684$.

Rosen, R., Brown, C., Heiman, J., Leiblum, S., Meston, C., Shabsigh, R., Ferguson, D. \& D'Agostino, R. Jr. (2000): The female sexual function index (fsfi): a multidimensional selfreport instrument for the assessment of female sexual function.J. Sex Marital Ther., 26:191-208.

Rosen C. (200o): Prevalence and risk factors of sexual dysfunction in men and women. Curr. Psychiatry Rep., 2(3):189-195.

Safarinejad, M.R. (2006): Female sexual dysfunction in population based study in Iran: prevalence and associated risk factors. Int. J. Impot Res., 18(4):382-395.

Salonia A, Munarriz RM, Naspro R, Nappi RE, Briganti A, Chionna R, Federghini, F., Mirone, V., Riratti, P., Goldstein, I., \& Montorsi, F. (2004): Women's sexual dysfunction: a pathophysiological review. BJUInt., 93:1156-1164.

Shull, B.L. (1999): Pelvic Organ Prolapse : Anterior, Superior And Posterior Vaginal Segment Defects. Am.J. Obs. Gynecol., 181(1):6-11.

Symonds, T., Boolell, M. \& Quirk, F..(2005): Development of a questionnaire on sexual quality of life in women. ISex Marital Ther. 31(5):385-397.

Telsiz M.(1998): Adolescents viws on the parental roles: A Turkis study,Int. J.Soc. Family., 28(4):69-77.

Tepavcevic, D.K., Kostic, J., Basoroski, I.D., Stojsavljevic, N., Pekmezovic, T. \& Drulovic, J. (2008): The impact of sexual dysfunction on the quality of life measured by MSQoL-54 in patients with multiple sclerosis. Mult. Scler,. 14(8):1131-1136.

WHO (2002): Defining sexual health. Report of a technical consultation on sexual health, 28-31 January 2002, World Health Organization. Geneva.

Yucel, D. \& Gassanov, M.A. (2010). Exploring actor and partner correlations of sexual satisfaction among married couples, Soc. Sci.Res., 39(5):725-738. 